12

\title{
Особенности формирования разряда в ускорителе плазмы и структура струи, истекающей в вакуум
}

\author{
(C) В.Ю. Горяинов, ${ }^{1}$ М.Е. Викторов, ${ }^{2}$ А.В. Водопьянов, ${ }^{2}$ А.В. Воронин ${ }^{1}$ \\ ${ }^{1}$ Физико-технический институт им. А.Ф. Иофрфе РАН, \\ 194021 Санкт-Петербург, Россия \\ ${ }^{2}$ Федеральный исследовательский центр Институт прикладной фризики РАН, \\ 603950 Нижний Новгород, Россия \\ e-mail: vgoryainov@mail.ioffe.ru
}

Поступило в Редакцию 30 апреля 2020 г.

В окончательной редакции 8 июля 2020 г.

Принято к публикации 24 июля 2020 г.

\begin{abstract}
Представлены результаты исследования структуры струи, создаваемой коаксиальным ускорителем плазмы с конической вставкой в области формирования разряда. С помощью скоростной электронно-оптической камеры обнаружена неоднородная структура светящихся фракций аргоновой и дейтериевой струй. Обнаружены колебания интенсивности излучения струи с характерной частотой $0.3-0.9 \mathrm{MHz}$. Струя аргоновой плазмы состояла из расходящихся от оси фрагментов, плазма рекомбинировала через $20 \mu$ s после начала тока. Струя дейтериевой плазмы напоминала хлопья. Интенсивность ее излучения значительно уменьшалась к $8 \mu \mathrm{s}$. Характерные частоты неоднородностей излучения на оси струи для аргона составляли $\sim 0.09 \mathrm{~cm}^{-1}$, для дейтерия $\sim 0.3 \mathrm{~cm}^{-1}$. Исследования поведения разряда в ускорителе плазмы показали, что диффузный разряд инициировался у основания конической вставки. Через $0.5 \mu$ s разряд выходил на наружную границу вставки, контрагировался и горел между центральным и наружным электродами. Выход разряда из ускорителя наблюдался спустя $3 \mu \mathrm{s}$ и сопровождался свечением торца центрального электрода. В ходе измерения температуры боковой поверхности наружного электрода с помощью тепловизора выявлена локализация нагрева вблизи края конусной вставки и на выходе ускорителя. Результаты исследований могут быть использованы для ионизации газа, в облучении материалов, а также для моделирования в лабораторных условиях взаимодействия потоков плазмы с магнитным полем в космосе.
\end{abstract}

Ключевые слова: разряд, электронно-оптическая камера, плазма, аргоновая и дейтериевая струи.

DOI: 10.21883/JTF.2021.02.50370.153-20

\section{Введение}

Источники плазменных струй, движущихся с большой кинетической энергией, представляют значительный интерес. С использованием таких струй успешно проводится подпитка топливом установок с магнитным удержанием плазмы, облучение конструкционных материалов, а также лабораторное моделирование взаимодействия потоков плазмы с магнитным полем в космосе [1-3]. Опубликовано большое количество работ по взаимодействию плазменных струй с материалами [4], внешним магнитным полем $[2,3,5]$. Однако работ, посвященных изучению структуры свободно вытекающей струи в вакуум, мало [6]. Изучение особенностей струи, а также выяснение основных факторов, влияющих на поведение разряда, позволит управлять параметрами и находить наиболее энергетически эффективные режимы работы ускорителя плазмы с максимально возможной энергией потока. Для решения этих задач необходимо применять диагностики с пространственным и высоким временным разрешением.

Целью настоящей работы является изучение структуры струи и поведение разряда в оригинальном коаксиальном ускорителе плазмы [7] с помощью ско- ростной электронно-оптической и инфракрасной камер. Некоторые результаты таких исследований уже были представлены в работах $[4,8]$. Отмечалось неоднородное свечение струи, наблюдаемое с помощью стрик-камеры через щель, расположенную вдоль направления потока, с временем экспозиции $10-30 \mu \mathrm{s}$, однако пространственная картина излучения была недоступна. Настоящая работа является продолжением ранее начатых экспериментальных исследований ускорителя плазмы. Основные усилия были сконцентрированы на изучении поведения структуры струи и особенностях формирования разряда внутри коаксиального ускорителя с помощью высокоскоростной камеры.

\section{1. Эксперимент}

Исследования проводились на стенде, который состоял из вакуумной камеры объемом $2.5 \mathrm{~m}^{3}$ с остаточным давлением $10^{-5}$ Torr, коаксиального ускорителя плазменной струи и диагностик для измерения ее параметров (рис. 1).

К вакуумному затвору камеры через керамический изолятор присоединялся плазменный ускоритель. Диаметры наружного и внутреннего электродов ускорителя 
составляли 46 и $10 \mathrm{~mm}$ соответственно. Электроды были выполнены из нержавеющей стали. Длина электродов составляла $110 \mathrm{~mm}$. На начальном участке ускорителя была установлена коническая вставка, соединенная с наружным электродом. С помощью такой конструкции удалось получить струю плазмы с наибольшими энергетическими параметрами [7] (рис. 2).

Питание ускорителя осуществлялось с помощью емкостного накопителя $160 \mu \mathrm{F}$, напряжением $5 \mathrm{kV}$. Разряд производился после импульсной подачи напряжения на электроды ускорителя с максимальным значением тока до $120 \mathrm{kA}$ и длительностью около $15 \mu \mathrm{s}$. Параметры разряда были выбраны экспериментально при условии минимального поступления примесей с электродов. Подводимая к электродам ускорителя энергия в однократном импульсе составляла $2 \mathrm{~kJ}$. Типичная форма сигналов тока, протекающего по электродам ускорителя, а также напряжения, приведены на рис. 3.

В качестве рабочих газов, с помощью которых инициировался разряд в ускорителе, использовались легкий дейтерий и тяжелый - аргон. Напуск рабочего газа осуществлялся через боковую поверхность наружного электрода на начальном участке ускорителя с помощью клапана электродинамического типа. Длительность открытого состояния клапана составляла $250-400 \mu \mathrm{s}$. Оптимальная задержка между началом напуска газа и инициацией разряда составляла $400 \mu \mathrm{s}$. Давление рабочего газа над клапаном варьировалось от 1.7 до $3 \mathrm{bar}$. Генерируемая струя имела температуру электронов около $1 \mathrm{eV}$, энергию направленного потока около $300 \mathrm{~J}$ на расстоянии $0.5 \mathrm{~m}$ [7].

Регистрация свечения разряда внутри ускорителя (положение $B$, рис. 1$)$, а также излучения струи плаз-

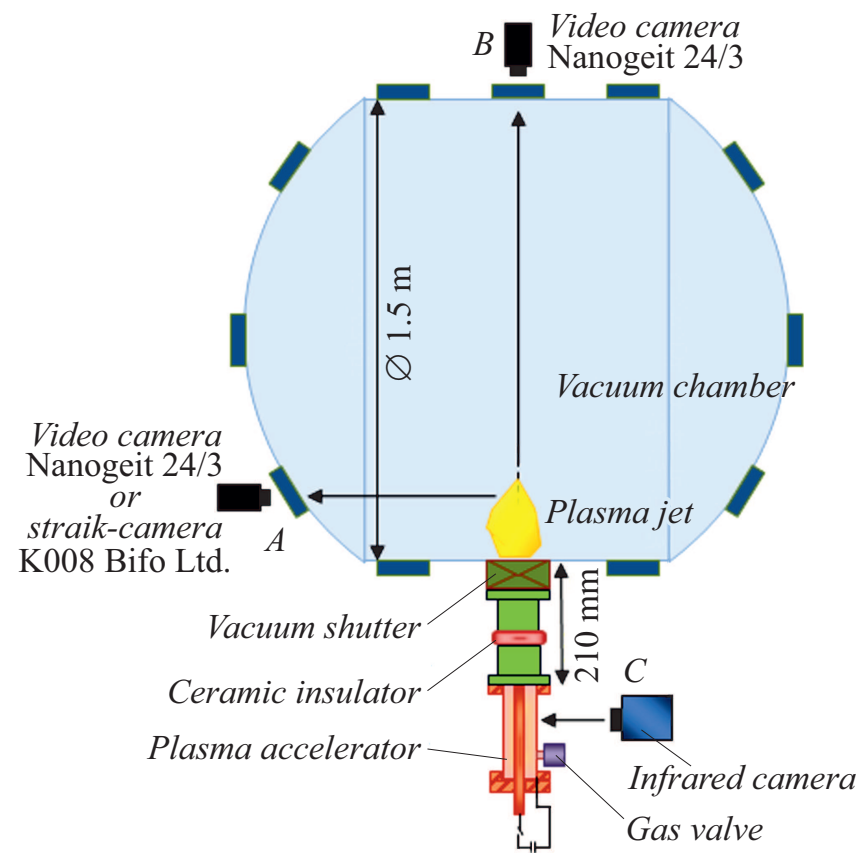

Рис. 1. Схема стенда ускорителя плазмы с диагностиками.

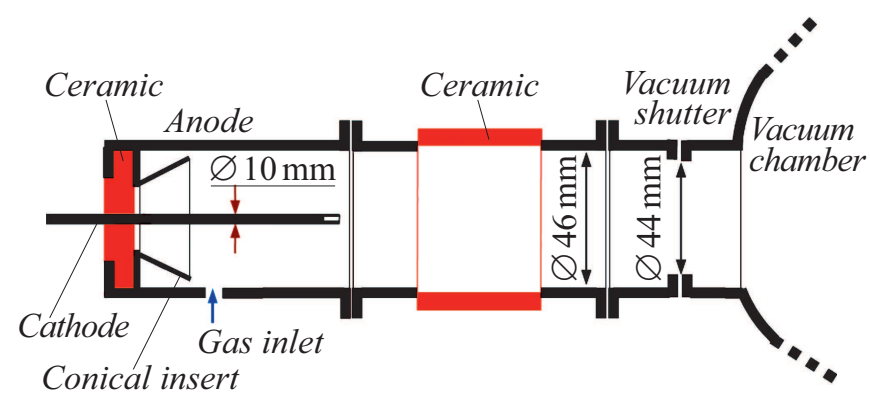

Рис. 2. Схема коаксиального ускорителя плазмы, присоединенного к вакуумной камере.

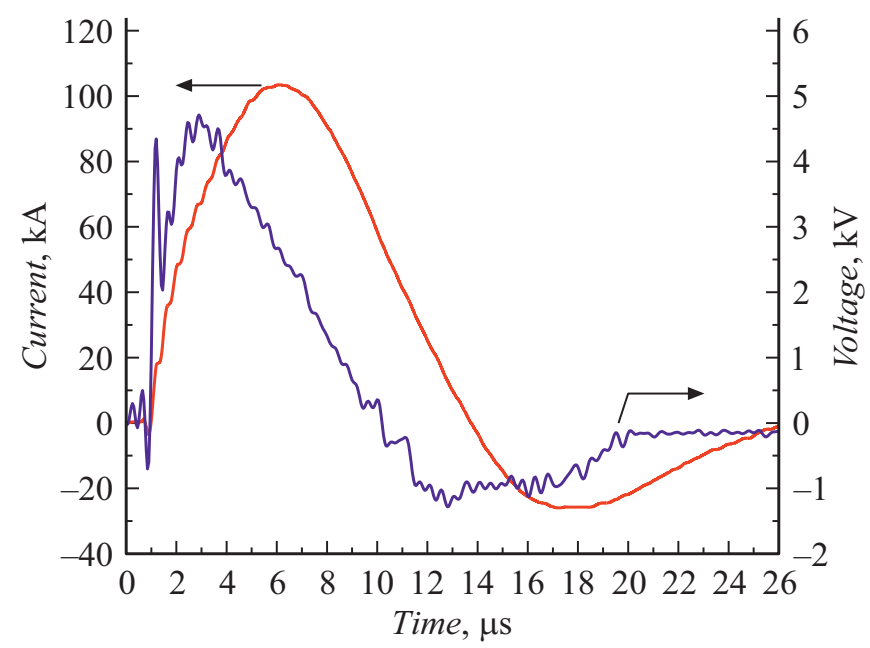

Рис. 3. Зависимости тока и напряжения ускорителя от времени.

мы на выходе (положение $A$, рис. 1) проводилась с помощью однокадровой электронно-оптической камеры Наногейт-24/3 (НПК ВидеоСКАН, Россия) с минимальным временем экспозиции $20 \mathrm{~ns}$ и диапазоном длин волн $400-800 \mathrm{~nm}$. Эволюция структуры струи при одинаковых физических условиях эксперимента была получена в течение серии последовательных разрядов. Запуск камеры производился по сигналу с датчика тока ускорителя плазмы с управляемой величиной временной задержки. Распределение температуры на стенке наружного электрода ускорителя измерялось с помощью инфракрасной камеры в диапазоне 3.7-4.3 $\mu \mathrm{m}$ (положение $C$, рис. 1). Исследования движения фронта ионизации в ускорителе проводились с помощью оптической стрик-камеры K008 (Bifo Comp., Россия) с длительностью экспозиции $10-30 \mu \mathrm{s}$ (положение $A$, рис. 1$)$.

\section{2. Результаты измерений структуры струи}

Неоднородная структура струи на выходе ускорителя плазмы наблюдалась ранее и была представлена в работе [8]. С помощью оптической стрик-камеры, распо- 

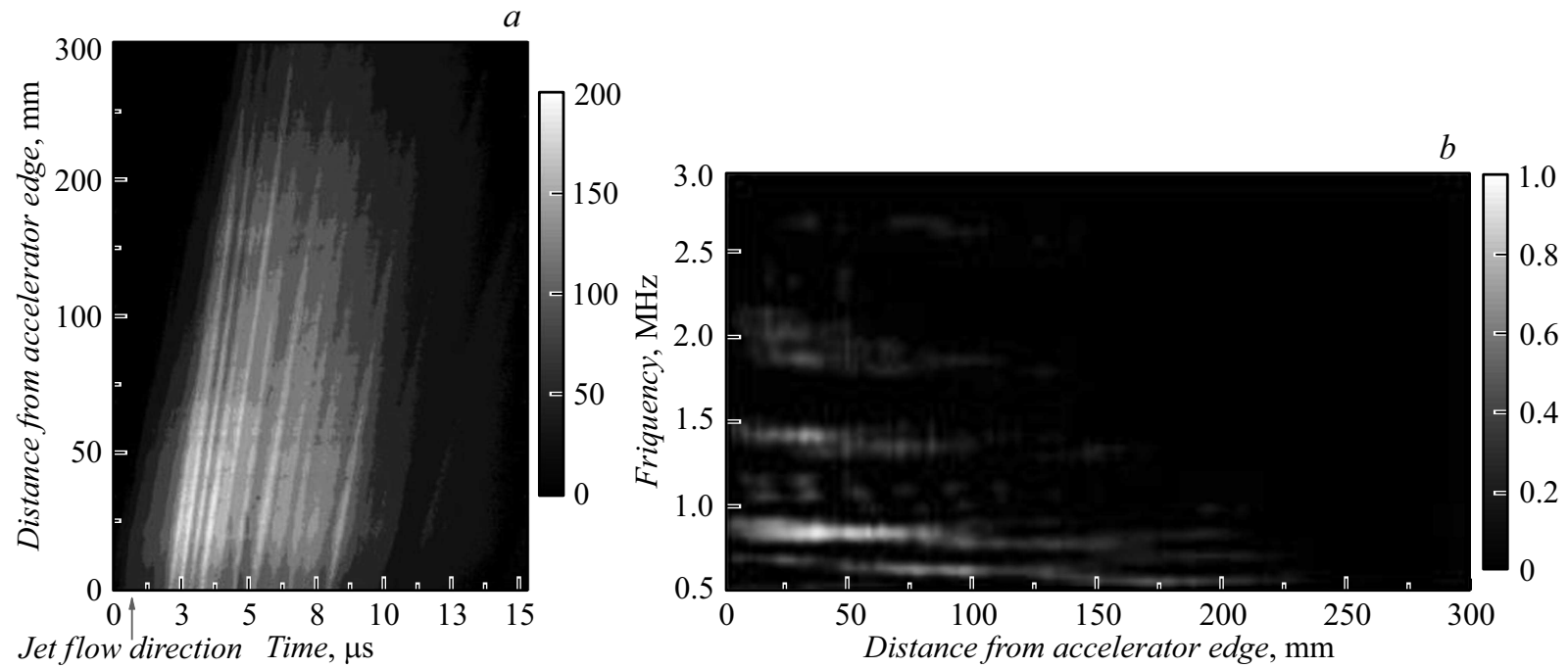

Рис. 4. $a$ - свечение струи, наблюдаемое с помощью стрик-камеры через щель, расположенную вдоль направления распространения струи. $b-$ зависимость амплитуды частот следования фрагментов струи от расстояния до ускорителя. Газ аргон, давление над клапаном $1 \mathrm{~atm}$. Длина электродов - $220 \mathrm{~mm}$.

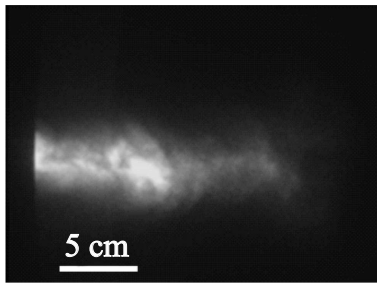

$4.4 \mu \mathrm{s}$

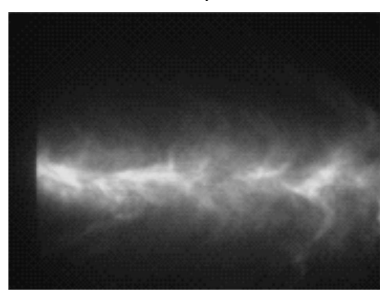

$15 \mu \mathrm{s}$

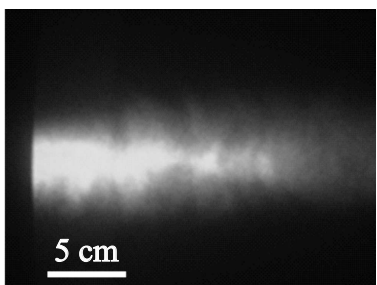

$4.3 \mu \mathrm{s}$

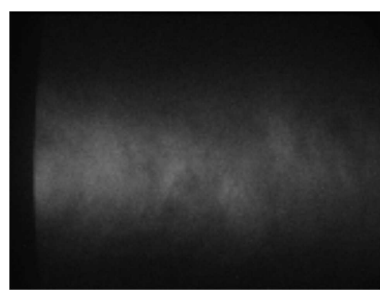

$15 \mu \mathrm{s}$

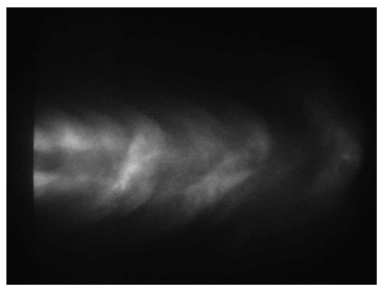

$5 \mu \mathrm{s}$

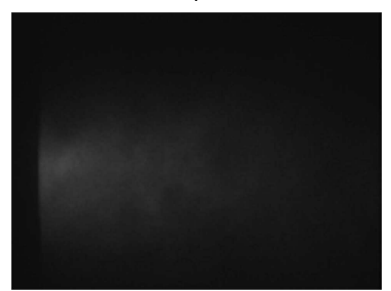

$20 \mu \mathrm{s}$

Argon

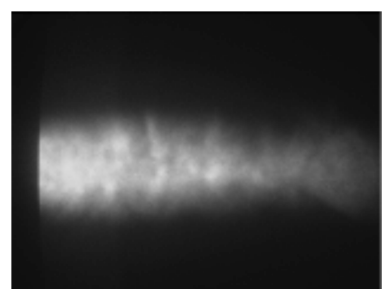

$5 \mu \mathrm{s}$

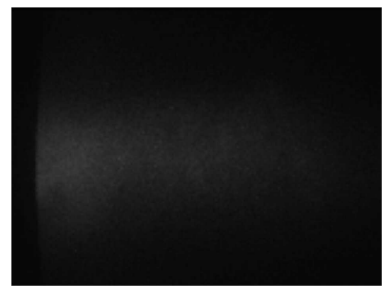

$20 \mu \mathrm{s}$

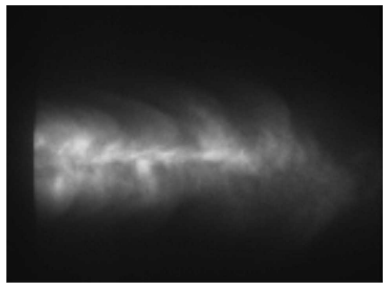

$7 \mu \mathrm{s}$

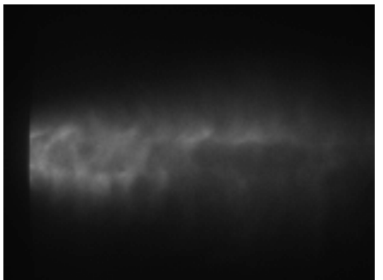

$8 \mu \mathrm{s}$

\section{Deuterium}

Рис. 5. Вид сбоку свечения плазменной струи на выходе коаксиального ускорителя, измеренного с различным временем задержки относительно начала тока ускорителя. Длительность экспозиции $20 \mathrm{~ns}$. Давление над клапаном $3 \mathrm{~atm}$. Длина электродов - $110 \mathrm{~mm}$. 

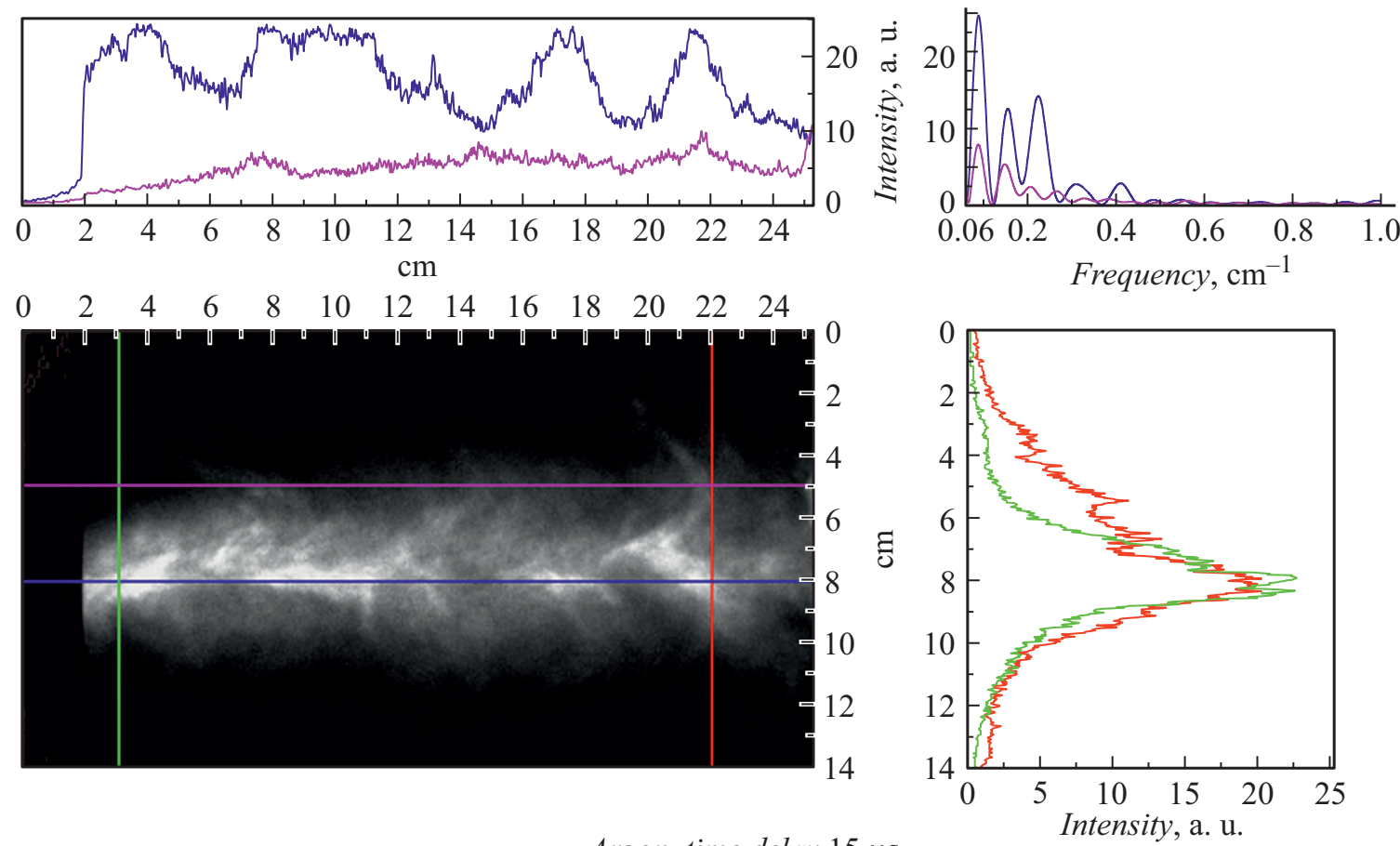

Argon, time delay $15 \mu \mathrm{s}$
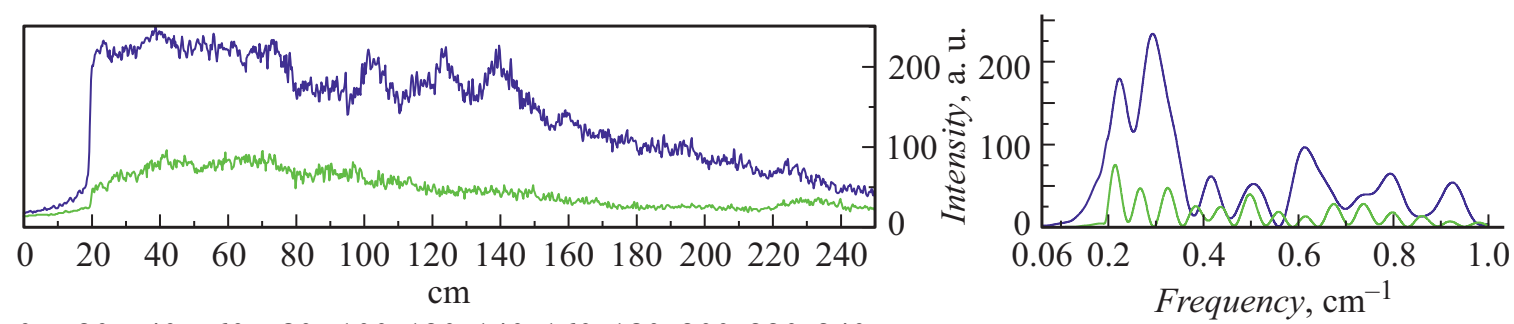

$\begin{array}{lllllllllllll}0 & 20 & 40 & 60 & 80 & 100 & 120 & 140 & 160 & 180 & 200 & 220 & 240\end{array}$
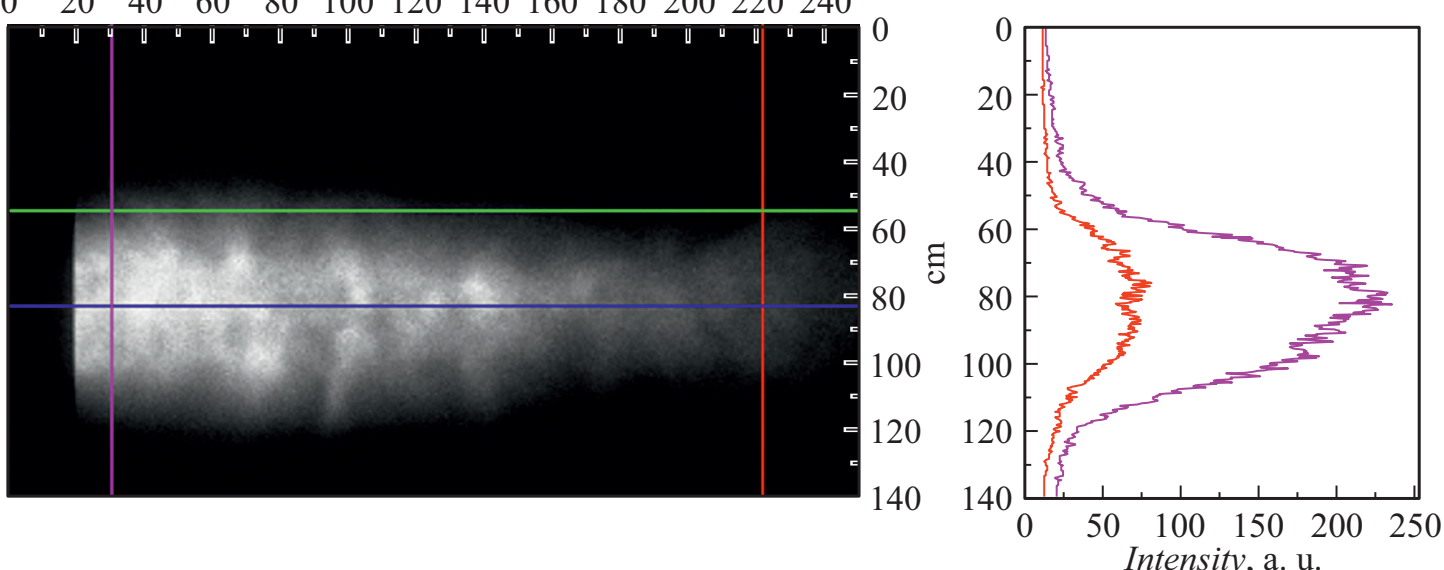

Deuterium, time delay $5 \mu \mathrm{s}$

Рис. 6. Профили интенсивности излучения струи и фурье-спектр, измеренные вдоль выделенных направлений на фотографиях. Длительность экспозиции $20 \mathrm{~ns}$.

ложенной в положении $A$, рис. 1, был обнаружен периодический характер интенсивности излучения струи. Периодическое свечение, наблюдаемое через щель, расположенную вдоль направления распространения струи, представлено на рис. 4, $a$. По горизонтальной оси отложено время от начала тока ускорителя, а по верти- кальной - расстояние от конца ускорителя. Видимые на рисунке наклонные полосы соответствовали отдельным фракциям струи, а их наклон определял скорость распространения каждой фракции. Скорость движения ионизационного фронта вычислялась по тангенсу угла наклона полос и составляла от 100 до $200 \mathrm{~km} / \mathrm{s}$. На 


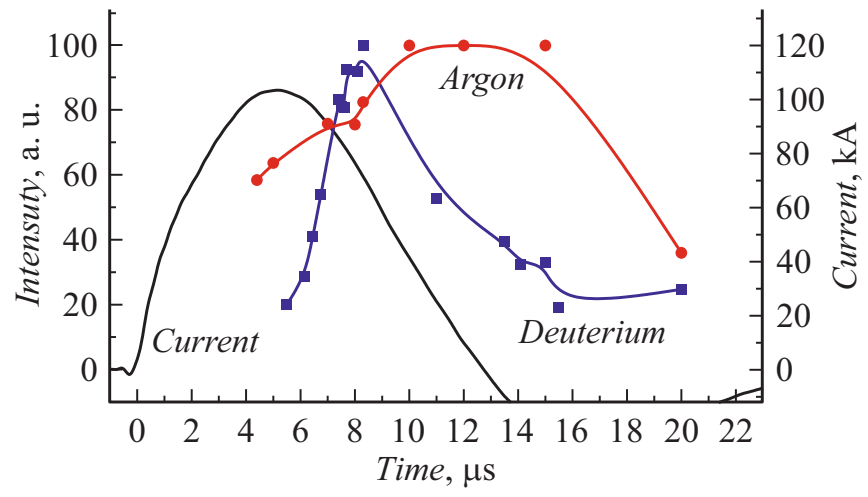

Рис. 7. Зависимости интегральной по пространству, ограниченному размерами изображения, интенсивности свечения струи от времени задержки относительно начала тока.

рис. $4, b$ представлено изменение частоты следования вылетающих фрагментов струи по мере ее удаления от ускорителя. Видно, что основная частота излучения $\sim 0.9 \mathrm{MHz}$ на большом отдалении уменьшается, что может говорить о том, что со временем фракции излучения отстают друг от друга и расходятся. Основная частота колебаний излучения в зависимости от разряда ускорителя варьировалась в диапазоне $0.3-0.9 \mathrm{MHz}$.

Регистрация пространственной картины излучения плазменной струи производилась с помощью видеокамеры Наногейт-24/3. Фотографии свечения плазмы на выходе коаксиального ускорителя с различным временем задержки относительно начала тока представлены на рис. 5. Видно, что примерно к 5-7 $\mu$ s длина струи превышала $0.25 \mathrm{~m}$. Фотографии были получены в течение серии последовательных разрядов, при этом наблюдаемая неоднородная структура излучения повторялась. Видеокадры подтвердили прерывистую структуру струи, обнаруженную ранее с помощью стрик-камеры. Наблюдалось заметное отличие между характером излучения струй аргона и дейтерия. Видно, что излучение дейтериевой плазмы значительно уменышилось к $8 \mu \mathrm{s}$, однако аргоновая плазма полностью рекомбинировала лишь к $20 \mu \mathrm{s}$. Отличие в длительности видимого излучения для разных сортов газа может быть связано с преобладанием тройной рекомбинации в наблюдаемых процессах, поскольку характерное время тройной рекомбинации зависит от массы частицы иона как $\tau_{\text {triple recomb }} \sim \sqrt{m_{i}}[9]$.

Профили интенсивности излучения и фурье-спектр, измеренные вдоль оси и по радиусу струи для различных родов газа, представлены на рис. 6. Наблюдалась прерывистая картина излучения. В струе аргона видны неоднородности в виде отдельных фрагментов, расходящихся от оси направленного движения. Размеры неоднородностей излучения дейтериевой струи были меньше размеров неоднородностей, наблюдаемых в аргоне. Видно, что наибольшая модуляция интенсивности прослеживалась вблизи оси струи для аргона и дейтерия. При удалении от оси на расстояние $2.5 \mathrm{~cm}$ модуляция интенсивности излучения практически исчезала. В струе аргона наблюдалась характерная модуляция свечения на частотах $0.09,0.15$ и $0.23 \mathrm{~cm}^{-1}$, в струе дейтерия - 0.2 и $0.3 \mathrm{~cm}^{-1}$.

На рис. 7 представлена зависимость интегральной интенсивности свечения струи по пространству, ограниченному размерами изображения, от времени задержки. Видно, что для аргоновой и дейтериевой плазмы характер зависимости интегрального свечения соответствовал зависимости тока ускорителя с задержкой в несколько микросекунд. Однако в аргоне времена нарастания и спада излучения плазмы оказались существенно больше, чем в дейтерии. Это может быть следствием различия характерных времен ионизации и рекомбинации используемых газов.

Регистрация свечения разряда внутри ускорителя (вид с торца) проводилась с помощью видеокамеры Наногейт-24/3, находящейся в положении $B$, рис. 1 . Свечение разряда внутри коаксиального плазменного ускорителя с различным временем задержки относительно начала тока представлено на рис. 8. Длительность экспозиции составляла $20 \mathrm{~ns}$. Видно, что диффузный разряд инициировался у основания конической вставки. Спустя $0.5 \mu \mathrm{s}$ разряд выходил на наружную границу конусной вставки, контрагировался и в виде токовой перемычки горел между центральным и наружным электродами. Выход разряда из ускорителя наблюдался приблизительно через $3 \mu$ s после начала роста тока и сопровождался свечением торца центрального электрода. Сорт рабочего газа не влиял на поведение разряда. С целью исследования вращения токовой перемычки была произведена регистрация разряда с длительностью экспозиции $3 \mu \mathrm{s}$. В этих условиях не было обнаружено размытия разряда в азимутальном направлении. Следовательно, можно сделать вывод об отсутствии вращения токовой перемычки в ускорителе за время импульса тока.

Термограмма наружного электрода с большой достоверностью могла характеризовать наиболее вероятное положение разряда в ускорителе. С этой целью были проведены измерения температуры боковой поверхности наружного электрода с помощью тепловизора в спектральном диапазоне 3.7-4.8 $\mu \mathrm{m}$, временем интегрирования $1 \mathrm{~ms}$ и частотой кадров $200 \mathrm{~Hz}$. Схема съемки боковой поверхности ускорителя показана на рис. 1, тепловизор располагался в положении $C$. Внешний диаметр наружного электрода из нержавеющей стали составлял $50 \mathrm{~mm}$, толщина стенки $-2 \mathrm{~mm}$. Для устранения бликов боковая поверхность электрода была зачернена сажей. На рис. 9 представлена термограмма боковой поверхности наружного электрода и зависимость изменения температуры вдоль выделенного направления, отмеченного на термограмме. Виден значительный нагрев наружной стенки электрода на начальном участке ускорителя. Разница температур до и после прохождения единичного импульса составляла $3.5^{\circ} \mathrm{C}$. Наружный электрод в области отрыва плазменного сгустка от электродов нагревался менее, чем на $1.2^{\circ} \mathrm{C}$. Такая картина прогрева 


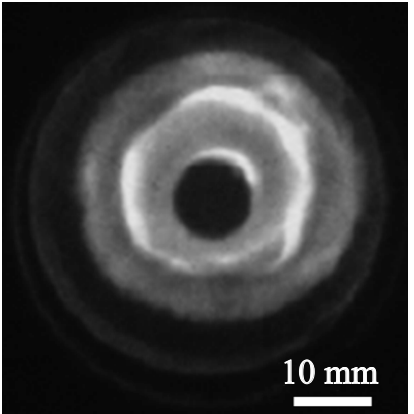

$0.04 \mu \mathrm{s}$

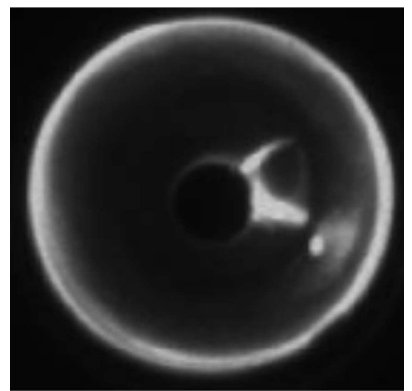

$1 \mu \mathrm{s}$

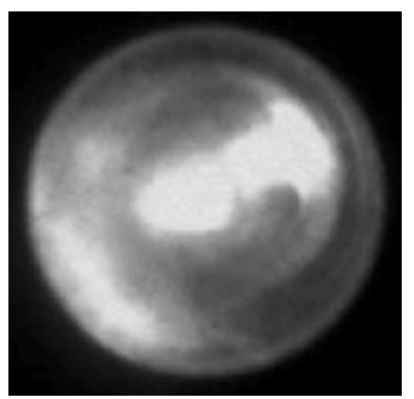

$7 \mu \mathrm{s}$

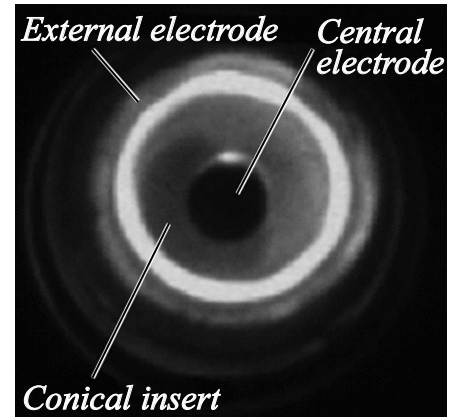

$0.2 \mu \mathrm{s}$

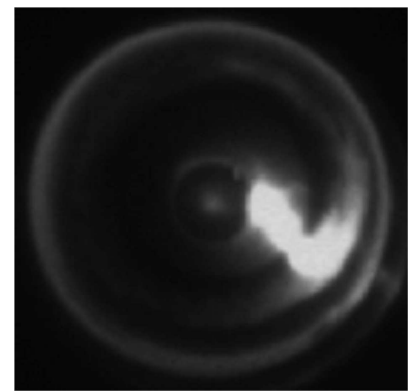

$2 \mu \mathrm{s}$

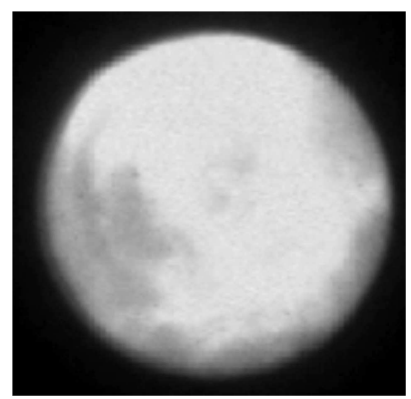

$10 \mu \mathrm{s}$

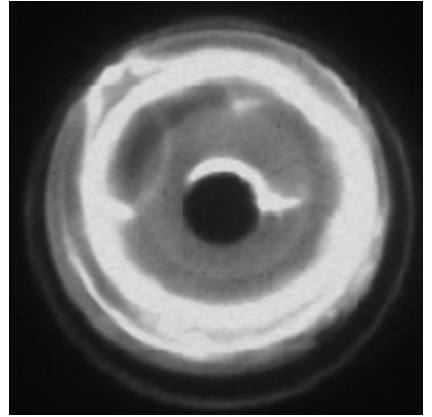

$0.5 \mu \mathrm{s}$

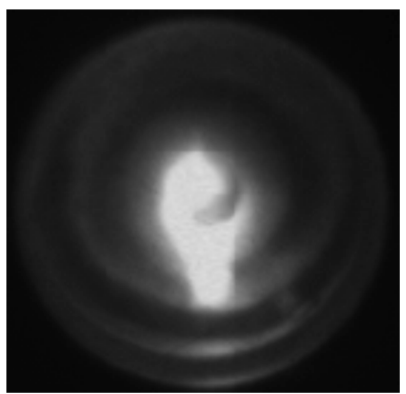

$3 \mu \mathrm{s}$

Рис. 8. Вид спереди свечения дейтериевого разряда внутри коаксиального плазменного ускорителя с различным временем задержки относительно начала тока. Длительность экспозиции 20 ns.
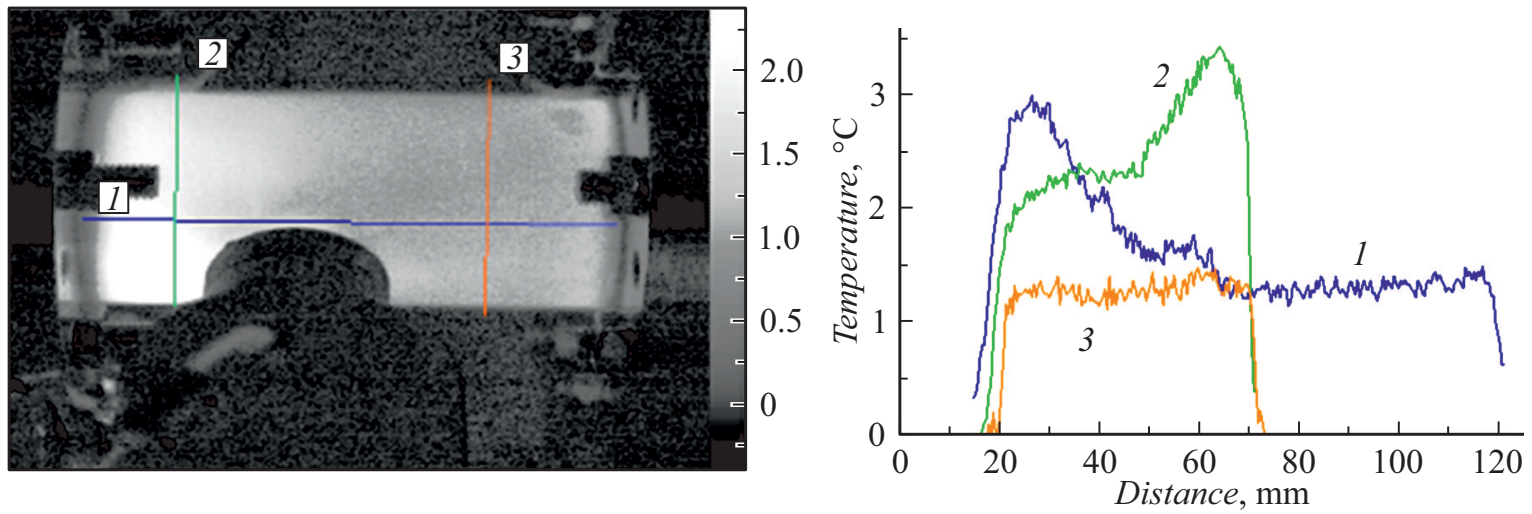

Рис. 9. Термограмма боковой поверхности ускорителя после разряда спустя $5 \mathrm{~ms}$.

электродов повторялась регулярно для струи плазмы с высокой кинетической энергией.
Таким образом, измерение температуры боковой поверхности наружного электрода позволило определить 
наиболее продолжительное положение разряда в ускорителе. Можно предположить, что на начальном участке ускорителя происходит локализация разряда вблизи края конусной вставки, а на выходе ускорителя горит диффузный дуговой разряд. Средний участок электрода разряд проходил быстро, из-за чего эта область не успевала сильно нагреваться.

\section{Заключение}

Проведено исследование структуры струи, создаваемой коаксиальным ускорителем плазмы. С помощью скоростной электронно-оптической камеры обнаружена неоднородная структура струи плазмы. Фурье-анализ проявил колебания интенсивности излучения с характерными частотами 0.3-0.9 MНz. Наблюдалось заметное отличие между характером излучения струй аргона и дейтерия. Струя аргоновой плазмы состояла из расходящихся от оси фрагментов, плазма рекомбинировала через $20 \mu \mathrm{s}$. В дейтериевой струе была обнаружена неоднородная структура без расходящихся от оси потоков. Интенсивность свечения дейтериевой плазмы значительно уменьшилась к $8 \mu \mathrm{s}$. Частоты неоднородностей вблизи оси струи для плазмы в аргоне составляли $\sim 0.09 \mathrm{~cm}^{-1}$, а в дейтерии $-\sim 0.3 \mathrm{~cm}^{-1}$. Характер зависимости интегрального свечения от времени соответствовал зависимости тока ускорителя с задержкой в несколько микросекунд.

Исследования формирования и эволюции движения разряда в ускорителе плазмы с помощью высокоскоростной оптической камеры показали, что диффузный разряд инициировался у основания конической вставки. К концу $0.5 \mu$ s разряд выходил на наружную границу вставки, контрагировался и горел между центральным и наружным электродами. Выход разряда из ускорителя наблюдался к началу $3 \mu \mathrm{s}$ и сопровождался свечением торца центрального электрода. Сорт рабочего газа не влиял на поведение разряда.

Измерение температуры боковой поверхности наружного электрода позволило определить наиболее продолжительное расположение разряда в ускорителе. На начальном участке ускорителя происходила локализация разряда вблизи края конусной вставки, а на выходе ускорителя наблюдался однородный нагрев внешнего электрода - горел диффузный дуговой разряд. Средний участок электрода разряд проходил быстро, из-за чего эта область не успевала сильно нагреваться.

Результаты исследований могут быть использованы для разработки технологии пробоя и ионизации газа, а также в технологиях получения новых материалов с помощью плазменной струи.

\section{Финансирование работы}

Экспериментальный образец коаксиального ускорителя плазменной струи был изготовлен и испытан в рамках соглашения с Минобрнауки РФ (идентификатор проекта RFMEFI58519X0007). Работа выполнена при поддержке РФФИ, проект \# 18-29-21037, поддержана Министерством науки и высшего образования Российской Федерации в рамках государственного задания в сфере науки по проекту № 0784-2020-0020.

\section{Благодарности}

Экспериментальный стенд для проведения испытаний плазменной пушки создан и поддерживается ФТИ им. А.Ф. Иоффе.

\section{Конфликт интересов}

Авторы заявляют, что у них нет конфликта интересов.

\section{Список литературы}

[1] M. Viktorov, S. Golubev, A. Vodopyanov. Plasma Phys. Control. Fusion, 61, 035001 (2019).

[2] C. Hsu Scott C., Paul M. Bellan. Monthly Notices of the Royal Astronomical Society, 334 (2), 257 (2002).

[3] S. Yun Gunsu, You Setthivoine, Paul M. Bellan. Nucl. Fusion, 47 (3), 181 (2007).

[4] А.В. Анкудинов, А.В. Воронин, В.К. Гусев, Я.А. Герасименко, Е.В. Демина, М.Д. Прусакова, Ю.В. Судьенков. ЖТФ, 84 (3), 36 (2014). [A.V. Ankundinov, A.V. Voronin, V.K. Gusev, Ya.A. Gerasimenko, E.V. Demina, M.D. Prusakova, Yu.V. Sud'enkov. Techn. Phys., 59 (3), 346 (2014).]

[5] H. Alfven, L. Lindberg, P. Mitlid. J. Nucl. Energy, Part C Plasma Phys., 1, 116 (1960).

[6] J. Wiechula, C. Hock, M. Iberler, T. Manegold, A. Schonlein, J. Jacoby. Phys. Plasmas, 22, 043516 (2015).

[7] А.В. Воронин, В.Ю. Горяинов, В.К. Гусев. ЖТФ, 90 (6), 1028 (2020). [A.V. Voronin, V.Yu. Goryainov, V.K. Gusev. Tech. Phys., 65 (6), 987 (2020).]

[8] А.В. Воронин, В.К. Гусев, Е.В. Демина, Г.С. Курскиев, В.Б. Минаев, А.Н. Новохацкий, Ю.В. Петров, Н.В. Сахаров, Ю.В. Судьенков, С.Ю. Толстяков. В сб. Физико-химические аспекты предельных состояний и структурных превращений в сплошных средах, материалах и технических системах. Вып. 1 под ред. Ю.В. Петрова (Политехника, Санкт-Петербург, 2017), с. 110.

[9] А.М. Прохоров (ред.). Физический энщиклопедический словарь (Советская энциклопедия, М., 1983) 